\title{
ПРИРОДА И СУЩНОСТЬ КРИПТОВАЛЮТЫ
}

\author{
М. Г. Жигас, С. Н. Кузьмина \\ Байкальский государственный университет, г. Иркутск, Российская Федерация
}

\section{Информация о статье}

Дата поступления

11 апреля 2018 г.

Дата принятия к печати 21 мая 2018 г.

Дата онлайн-размещения 8 июня 2018 г.

\section{Ключевые слова}

Криптовалюта; блокчейн; криптография; нанотехнологии; транзакции; рыночная стоимость; цифровой актив; фиатные деньги; криптобиржи; цифровая пиринговая наличность; электронные платежные системы

\begin{abstract}
Аннотация
В статье исследовано изменение процесса жизнедеятельности общества и революция в сфере IT-технологий, которые приводят к трансформации денежных форм и платежных систем. Сопоставлены изменения на уровне нового технологического уклада от низкоуровневых к более высоким и прогрессивным, сорормулированы причины появления новых электронных денежных средств. Дана характеристика криптовалюты, проанализированы сущность и природа ее происхождения. Рассмотрены основные функции денег применительно к криптовалюте. Авторами предложен новый термин - «псевдоденьги» и описана система цифровой пиринговой наличности. Высказаны суждения об имеющихся функциях криптовалюты и показаны дальнейшие возможности ее развития на фоне изменения рыночных отношений, возникновения новых фрорм хозяйствования и электронных платежных систем. Охарактеризованы особенности криптовалют, сформулированы их преимущества и недостатки. Выявлена специфика функционирования криптовалюты в своей уникальной электронной платежной системе, наличие которой является обязательным условием ее существования.
\end{abstract}

\section{NATURE AND ESSENCE OF CRYPTUALS}

\author{
Margarita G. Zhigas, Svetlana N. Kuzmina \\ Baikal State University, Irkutsk, the Russian Federation
}

\section{Article info}

Received

April 11, 2018

Accepted

May 21, 2018

Available online

June 8, 2018

\section{Keywords}

Crypto currency; blockchain; cryptography; nanotechnology; transactions; market value; digital asset; fiat currency; cryptuals exchange; digital peer-to-peer cash; electronic payment systems

\begin{abstract}
The article considers the changes in the process of society living and the revolution of IT technologies, which also influenced the modification of monetary forms and payment systems. Changes are compared at the level of the new technological order from the lowest level to the highest and most progressive one, the reasons for the emergence of new electronic funds are formulated. Characteristics of the crypto currency, its nature and nature of its origin are given. The main functions of money in relation to the crypto currency are considered. A new term for pseudo money is introduced. A description of the process of digital peer-to-peer electronic cash is given. Opinions about the available functions of the crypto currency and further opportunities for its development against the background of changes in market relations, new forms of management and electronic payment systems are expressed. The specific features of the crypto currency are considered, its advantages and disadvantages are formulated. The peculiarity of crypto currency functioning in its unique EPS is considered, the availability of which is an indispensable condition for its existence.
\end{abstract}

цией, развитие IT-технологий стали важной потребностью общества. Социально-экономические отношения начали выходить за рамки товарно-денежных отношений повседневной жизни, постепенно перемещаясь в электронное пространство. оказали особое влияние на формирование социально-экономических отношений в жизнедеятельности людей. Владение информа- 
По мнению М. Г. Жигас и С. Н. Кузьминой, современный этап развития экономической системы характеризуется активным внедрением цифровых технологий в банковскую сферу. Реализация большого количества международных финансово-технологических стартапов, создание нового поколения потребителей банковских услуг, а также развитие технологий ведут к масштабной трансформации работы банков [1, с. 77].

Изменение процесса жизнедеятельности общества, революция в сорере IT-технологий оказали влияние также на видоизменение денежных форм и платежных систем. Так, Д. Е. Евсюков отмечает, что прогресс в информационных технологиях сделал возможным появление современных платежных систем, использующих последние достижения в этой области и позволяющих осуществлять банковские платежи не выходя из дома, расплачиваться в магазине пластиковой карточкой и приобретать товары через Интернет. С развитием современных платежных систем связано возникновение так называемых электронных, или цифрровых, денег [2, с. 58].

Вхождение в новый технологический уклад изменило технологические процессы от низкоуровневых к более высоким и прогрессивным, предусматривающим внедрение и развитие нанотехнологий, системы искусственного интеллекта, робототехники, мировых информационных сетей и т. д.

В. В. Пшеничников и А. В. Бабкин отмечают, что «появление электронных денежных средств, лишенных вещественного носителя всеобщего эквивалента, требует изучения их природы и родовой основы с учетом новых реалий постиндустриального экономического уклада» [3, с. 33].

Происходящие изменения привели к возникновению совершенно нового явления криптовалюты, в основе которой содержится применение технологии блокчейн. Это принципиально новая базовая технология. Ее потенциал до настоящего времени оценить не представляется возможным, но при этом она уже оказала большое влияние на финансово-экономическую сферу и стала новым достижением в криптографии.

Ю. В. Коречков и П. Б. Целищев указывают, что «под электронной сущностью криптовалюты понимается механизм обмена, цифровой актив, эмиссия и учет которых зачастую децентрализованы. Функционирование механизма эмиссии и обращения криптовалюты происходит в рамках распределенной компьютерной сети. При этом обычно вся информация о производимых транзакциях не шифруется и всегда доступна в открытом виде» $[4$, с. 14]. Принцип работы криптовалюты заключается в функционировании внутри компьютерной сети, где также происходит ее эмиссия и учет. При этом криптография в технологическом процессе построения цепочки транзакций используется как метод защиты, основанный на асимметричном шифрровании.

В последние годы общественный интерес к криптовалюте во всем мире стал возрастать на фоне ее большого количественного значения, широких возможностей использования, а также возникновения у криптовалюты рыночной стоимости. Причем криптовалюту начали активно сопоставлять с понятием «деньги», порой называя ее подвидом электронных денег.

Сущность того или иного экономического понятия выражается в его функциях, которые могут трансформироваться в условиях новых социально-экономических отношений в обществе, а также изменений, происходящих в денежно-финансовых отношениях. Тем не менее основным значением денег в современном мире является их непосредственное участие в операциях, имеющих экономическую и фринансовую составляющую, более того, деньги объединяют эти операции между собой и неразрывно связывают все процессы.

Исследования, проведенные К. Марксом в период XIX в., обосновали основные пять функций денег, которые остаются актуальными и в настоящее время: мера стоимости, средство обращения, средство платежа, средство накопления и мировые деньги [5].

Рассмотрим общепринятые функции денег применительно к криптовалюте.

Функция "мера стоимости». Это процесс измерения рыночной стоимости товара, услуг, оказанных работ, которая выражается деньгами в виде цены. Рассматривая указанную функцию относительно криптовалюты, можно сказать, что пока она не является общепринятым эквивалентом, выражающим стоимость, не имеет ценности и не может удовлетворять всеобщую потребность. Рыночную стоимость криптовалюта приобретает в процессе обмена на фииатные деньги или иные виды криптовалют в электронных платежных системах (ЭПС), в которых они обращаются, или в процессе деятельности криптобирж. Таким образом, в настоящий период она не является общепринятым эквивалентом меновой стоимости в виде цены и не отражает меру стоимости товаров, работ и услуг.

Функция «средство обращения». Эта функция проявляется в посредничестве денег в рамках процесса обмена на товар 
или оказываемые услуги и работы. По мнению Д. И. Розенберга, перечисленные выше функции денег очень связаны между собой: «...то, что в деньгах в качестве меры стоимости выражено лишь как идеальная мера, в их функции средства обращения выражено реально» [6]. Для того чтобы деньги были приняты в качестве средства обращения, они должны иметь стоимость и приниматься к обращению в обществе. Обращение криптовалюты в ЭПС в настоящее время не формирует заинтересованность общества как посредника в процессе приобретения товаров или услуг как в реальной жизни, так и при совершении расчетов и платежей в ЭПС.

Функция «средство платежа». Данная функция предусматривает возможность денег осуществлять расчеты в рамках выполнения долговых обязательств. Использование криптовалюты в настоящее время как средство платежа представляется весьма сомнительным. Выдача кредита в криптовалюте при нестабильной курсовой разнице и отсутствии меновой стоимости не вызывает общественного интереса.

Функции “средство накопления» и «мировые деньги». Рассматривая значение указанных ффункций по отношению к криптовалюте, можно сказать, что популярность криптовалют как средства для инвестиций и средства накоплений набирает обороты. Вопрос в том, действительно ли криптовалюта может быть средством накопления или общественный ажиотаж подогревается спекулянтами. Криптовалюта не является законным платежным средством.

Отметим, что на фроне уникальности технологий, лежащих в основе функционирования криптовалюты, и огромного интереса к ней со стороны общественных масс основные действия, производимые с криптовалютой, основываются на спекуляциях. Разговоры о появлении новой формы денег в обществе, безусловно, подогревают интерес, но по факту этот процесс подменяет понятие денег. Проанализировав основные функции денег по отношению к криптовалюте, считаем наиболее правильным в данный период применять к криптовалюте термин «псевдоденьги».

Элемент спроса криптовалюты по отношению к разным видам товаров и услуг или иному виду криптовалюты имеет различные категории обратимости. Причем в большинстве случаев отдельные виды криптовалют функционируют только в одной виртуальной среде. В таких электронно-платежных системaх использование криптовалюты как средства платежа или средства обмена на фриатные валюты или иные криптовалюты значительно ограничено как в рамках ЭПС, в которой обращается криптовалюта, так и за ее пределами.

Функции, которыми, как кажется, наделена криптовалюта, не относятся к функциям денег. Но нельзя не учитывать тот фракт, что в условиях развития рыночных отношений, форм хозяйствования, электронных платежных систем ит. д. вполне возможно изменение понимания экономической сущности денег, и тогда криптовалюта может занять свою нишу.

Первое описание принципа функционирования системы цифровой пиринговой наличности было отражено в статье С. Накамото, опубликованной 31 октября 2008 г. [7]. В своей работе исследователь предложил решение по созданию совершенно новой платежной системы на основе криптографического процесса. Основными ее преимуществами, с точки зрения автора, явились простота в расчетах, отсутствие посредников, контроль процесса всеми его участниками, снижение стоимости транзакций. Новая модель пиринговой системы предоставила возможность осуществлять расчеты между участниками сети напрямую, минуя всевозможных посредников. Примерно через год после публикации научной работы было создано первое программное обеспечение.

Дальнейшее развитие представленной технологии было обусловлено факторами развития общества. Появились новые возможности технологических процессов и компьютерных систем, изменились экономические процессы, начали развиваться криптографические методы защиты, возникли новые формы платежных инструментов и т. д.

По мнению Д. С. Вахрушева и О. В. Железова, «появление криптовалют - это следствие объективного процесса конкуренции между системами фиксации фактов перехода стоимости. Так, на сегодняшний день в мире представлено множество сервисов со своими достоинствами и недостатками. Криптовалюты в этом смысле являются новым этапом в развитии электронных денег, при этом они в состоянии удовлетворить современные возрастающие требования, предъявляемые к операциям с использованием электронных денег, а именно: моментальная скорость расчетов (от нескольких секунд до нескольких минут); отсутствие комиссии за совершение транзакций; анонимность расчетов; высокая степень защищенности операций; отсутствие необходимости конвертации в валюту страны производства расчетов» [8].

Специфика совершения расчетов в современном мире заключается в наличии по- 
средников, участвующих в данном процессе, что, безусловно, не может не отражаться на перечисленных выше факторах и возникновении преобразований в данных системах.

Однако не только процесс развития современных ЭПС, инновации в сети Интернет, совершенствование вычислительных и инфрормационных технологий выступили основой появления и дальнейшего вхождения в общественную жизнь криптовалюты. Новаторская работа нобелевского лауреата Фридриха А. Хайека «Частные деньги» послужила теоретической основой процесса создания криптовалюты, осмысления происходящего процесса и природы ее происхождения [9]. Основная мысль Ф. А. Хайека заключается в денационализации денег. Автор утверждал, что любой хозяйственный субъект должен иметь право на выпуск самостоятельной валюты, что создаст активный и конкурентный рынок. При этом он высказывал мнение о том, что у правительств нет причин иметь монополию на выпуск денежных средств и что наибольший спрос со стороны потребителя будет на ту валюту, которая окажется способной поддерживать стабильную стоимость. На фоне этого банки будут осуществлять более гибкое управление спросом на деньги, чем правительственные органы [там же].

В своей работе автор рассуждает о том, что конкуренция между частными валютами даст возможность осуществлять контроль за ее ценностью, а также поддерживать покупательную способность валюты и спрос на нее.

Основной идеей автора было обращение свободных денег на рынке, которые могут выпускаться разными органами. По словам Хайека, этот соревновательный процесс между валютами внутри экономического сообщества приведет к лучшей форме денег и к наибольшим экономическим выгодам [там же].

Рассуждения на эту тему, высказанные в 70-е гг. прошлого столетия, находят свое отражение в системе криптовалют и покупательском спросе на нее.

Вернемся к вопросу специфики криптовалют. Цифровая форма, в которой выпускается криптовалюта, состоит из криптографических записей, в то время как общепринятые национальные денежные средства выпускаются в форме знаков стоимости и имеют физическую форму.

Криптовалюта выпускается частными эмитентами, а национальные денежные средства - денежно-кредитными регуляторами.

Криптовалюта не дает гарантий различного рода юрисдикций. Только по соглашению сторон она может брать на себя отдельные функции, свойственные национальным платежным средствам, при этом обращаясь исключительно в поле виртуальной среды отдельного сетевого сообщества.

В настоящее время тема френомена криптовалют остается одной из самых обсуждаемых в общественных и экономических кругах.

В представленном анализе виртуальных валютных схем Европейского центрального банка криптовалюты определены как «электронное представление ценности, не используемое центральным банком, кредитным учреждением или эмитентом электронных денег, которое при определенных обстоятельствах может быть использовано как альтернатива деньгам»'.

Основными преимуществами криптовалюты, благодаря ее положительным характеристикам для пользователей, являются высокая информационная защита, экономия затрат и скорость при осуществлении расчетов, конфиденциальность. К слабым сторонам криптовалюты отнесем сложность контроля в Сети, высокую волатильность, отсутствие правового регулирования, а также то, что стоимость криптовалюты ничем не обеспечена. Все взаимоотношения выстраиваются только на доверии участников ЭПС.

Рассмотрим ряд статистических данных, характеризующих развитие криптовалют. В настоящее время в мире обращается 1583 их разновидности. По состоянию на 25 марта 2018 г. их совокупная капитализация составила 329,38 млрд дол. США². При большом разнообразии представленных криптовалют в мире наиболее популярными являются Bitecoin, Ethereum, Ripple, Litecoin (табл.).

Капитализация основных криптовалют (на 25 марта 2018 г.)

\begin{tabular}{|l|r|r|r|}
\hline $\begin{array}{c}\text { Криптова- } \\
\text { люта }\end{array}$ & Эмиссия & $\begin{array}{r}\text { Капита- } \\
\text { лизация, } \\
\text { млрд дол. } \\
\text { США }\end{array}$ & $\begin{array}{r}\text { Удель- } \\
\text { ный вес } \\
\text { капитали- } \\
\text { зации, \% }\end{array}$ \\
\hline Bitecoin, BTC & $16,938,237$ & 145,32 & 44,12 \\
\hline $\begin{array}{l}\text { Ethereum, } \\
\text { ETN }\end{array}$ & $98,400,942$ & 51,42 & 15,61 \\
\hline Ripple, XRP & $39,094,227,299$ & 24,95 & 7,58 \\
\hline $\begin{array}{l}\text { Bitecoin cash, } \\
\text { BCH }\end{array}$ & $17,036,450$ & 16,74 & 5,08 \\
\hline Litecoin, LTC & $55,778,656$ & 8,89 & 2,70 \\
\hline Прочие & & 82,06 & 24,91 \\
\hline \multicolumn{1}{|c|}{ Bсего } & & 329,38 & 100 \\
\hline
\end{tabular}

${ }^{1}$ European Central Bank. Virtual currency schemes - a further analysis / / ECB report. 2015. Febr.

2 URL: https: / / coinmarketcap.com/16. 
Ведущее место по капитализации криптовалют занимает Bitecoin, его удельный вес составляет 44,12\%, Ethereum с удельным весом 15,61\% традиционно занимает вторую позицию, у Ripple с удельным весом 7,58 \% третье место. В общей сложности на самые популярные криптовалюты приходится 75,09 \% от общего удельного веса капитализации криптовалют в мире. Данные показатели находятся в динамическом движении, удельный вес капитализации первой пятерки криптовалют постоянно перераспределяется, при этом имеет активную тенденцию к снижению. Например, по состоянию на 15 октября 2017 г. в капитализации криптовалют доля удельного веса Bitecoin составляла $54,22 \%$, a Ethereum - 18,43\%. При этом на удельный вес прочих криптовалют в их общем объеме приходилось 16,3 \%. Общее количество криптовалют на указанную дату составляло 1170 [10, с. 557].

Динамика снижения удельного веса первой пятерки криптовалют по отношению к их общему объему говорит о стадии активной популяризации криптовалюты и росте интереса общества к ней как к активу в целом, а также об использовании в инвестировании и иных, альтернативных видов криптовалют.

Анализ общей динамики капитализации криптовалют начиная с 29 апреля 2013 г. ${ }^{3}$ по 31 декабря 2016 г. свидетельствует о том, что рост капитализации был достаточно плавным и постепенным, без резких скачков. В указанный трехлетний период размер капитализации криптовалют вырос с 1,60 млрд до 17,71 млрд дол. США, т. е. более чем в десять раз. Однако, несмотря на такие существенные изменения, самым активным периодом роста рынка криптовалют стал 2017 год. По состоянию на 2 января 2017 г. капитализация рынка составляла 18,30 млрд дол. США, а на 1 января 2018 г. она выросла до 610,11 млрд дол. Таким образом, капитализация рынка криптовалют за 2017 г. увеличилась более чем в 33 раза.

Возникает вопрос, с чем связана такая популярность криптовалюты. Во-первых, происходит осознание того, что наступает новый период рыночных отношений. Во-вторых, в мировом сообществе возрастает интерес к реализации новых финансовых проектов.

Происходящие в системе денежных отношений изменения являются неизбежными и не остаются без внимания со стороны регуляторов всех стран мира, в том числе и Российской Федерации.

${ }^{3}$ URL: https: / / coinmarketcap.com/ru/charts.
В настоящее время в нашей стране на законодательном уровне проводится экспертно-аналитическое исследование на тему «Законодательное регулирование внедрения и практического применения современных финансовых технологий. Анализ международного опыта и модальностей адаптации в российской практике» ${ }^{4}$. Одна из основных задач научно-экспертной работы заключается в содержательном анализе новых финансовых технологий, в том числе криптовалют, которые выпускаются на основе технологического процесса блокчейн. Необходимо осуществить максимально точную оценку перспектив развития российского и международных финансовых рынков с учетом процесса адаптации потребительских рынков к возможным изменениям. На основе исследований также будет проведена экспертная оценка действующего законодательства. В дальнейшем это позволит создать нормативно-правовую базу, регулирующую вопросы обращения криптовалют.

В направлении формирования нормативно-правовой базы для регулирования криптовалют в Российской Федерации специалистами различных сорер деятельности ведется активная работа. Рассуждения о неактуальности темы криптовалют ушли в прошлое. Процесс роста и изменений крипторынка в течение 2017 г. позволяет сделать безусловный вывод о том, что законодательное регулирование криптовалюты - важное направление, которое даст возможность получить большую пользу для развития денежно-кредитной системы страны.

Президентом России в октябре 2017 г. Банку России и правительству было дано поручение в период до 1 июля 2018 г. обеспечить разработку поправок в нормативно-правовую базу по вопросам регулирования криптовалюты в России 5 . Также, согласно распоряжению президента, к указанному сроку будет определен статус технологических процессов, которые уже нашли свое применение в финансовой сорере.

В настоящее время финансовые регуляторы зарубежных стран мира активно обсуждают и исследуют вопросы, касающиеся создания благоприятного климата, способствующего дальнейшему развитию феномена криптовалют. Данная позиция

URL: http: / / zakupki.gov.ru/epz /order / notice / ok 44/view / common-info.html?regNumb er $=0173100009617000107$.

${ }^{5}$ URL: https: / /rg.ru/2017/10/24/vladimir-putinporuchil-podgotovit-popravki-o-kriptovaliute-do-1iiulia.html. 
подкрепляется наличием большого потенциала применения новых технологий в разных сорерах деятельности.

В апреле 2017 г. в Японии официальным платежным средством был признан любой тип криптовалют. На уровне правительства Японии вносятся поправки в нормативно-правовую базу, в дальнейшем руководство страны планирует более активное внедрение криптовалют в цифровую экономику страны.

В Южной Kopee популяризация криптовалют привела к повышенному спросу на них со стороны населения. На территории Кореи более чем в 6 тыс. магазинов уже сейчас можно осуществить расчетыв криптовалюте, при этом, по прогнозам экспертов, до конца года количество магазинов, принимающих к оплате криптовалюту, возрастет и составит не менее 8 тыс. ${ }^{6}$ При помощи криптовалють можно оплатить как товары первой необходимости (продукты питания, одежду), так и услуги, предоставляемые населению. Все расчеты в криптовалюте происходят через мобильное приложение, которое осуществляет конвертацию криптовалюты в традиционные денежные средства, поступающие на счет магазина или сервиса, оказывающего данные услуги.

В течение 2017 г. власти Китая провели мероприятия по ужесточению регулирования криптовалютного рынка на территории своей страны, запретили ICO и торговлю криптовалютой. При этом работа с криптовалютой является одной из основных задач на 2018 г. в рамках осуществления различных мер по защите национальной валюты Китая.

Криптовалюты функционируют исключительно в своей уникальной ЭПС, наличие

6 URL: https://cryptos.tv/v-yuzhnoj-koree-uzhebolee-chem-v-6000-magazinax-mozhno-rasplatitsyabitkoinom. которой является обязательным условием существования криптовалюты. В рамках обращения криптовалюты в уникальной ЭПС возникает ее рыночная стоимость. Единство криптовалюты и электронной платежной системы, в которой она обращается, выступает ее основным и уникальным свойством. Но представленные схемы обращения криптовалют в настоящее время не являются полноформатными средствами платежей, как это определяется в научной литературе.

Стандартных функций денежных средств у критовалюты нет, по этой причине в настоящее время мы не можем называть ее валютой в общепринятом смысле этого слова. Как средство платежа она весьма неэффрективна, для сохранения стоимости также является ненадежным активом. Криптовалюта в формате псевдоденег частично берет на себя функционал денежных средств только в поддерживаемых ею уникальных системах цифровой пиринговой наличности, но в ближайшем будущем не заменит общепринятое понятие денежных средств.

В настоящий период мировое сообщество в процессе развития криптовалют прилагает максимальные усилия к созданию благоприятных условий для функционирования нового технологического процесса. На первый план выходят вопросы дальнейшего изучения феномена криптовалют, выявления их уникальных функций с возможностью последующей трансформации в новые соеры экономического процесса. Переходный период текущего времени с глубоким изучением технологии криптовалют и ее применения позволит спроектировать результаты предстоящих изменений, которые на сегодня еще не имеют картину будущего, однако уже предопределены временем.

\section{СПИСОК ИСПОЛЬЗОВАННОЙ ЛИТЕРАТУРЫ}

1. Жигас М. Г. Современные тенденции использования цифровых технологий в банковской сфере / М. Г. Жигас, С. Н. Кузьмина // Евроазиатское сотрудничество : материалы междунар. науч.-практ. конф., Иркутск, 14-15 сент. 2017 г. - Иркутск, 2017. - С. 77-86.

2. Евсюков Д. Е. Электронные деньги и их влияние на денежную систему / Д. Е. Евсюков // Вестник Новосибирского государственного университета. Сер.: Социально-экономические науки. - 2002. - № 1. C. 58-71.

3. Пшеничников В. В. Электронные деньги как фактор развития цифровой экономики / В. В. Пшеничников, А. В. Бабкин // Научно-технические ведомости Санкт-Петербургского государственного политехнического университета. Экономические науки. - 2017. - T. 10, № 1. - C. 32-42. — DOI: 10.18721/JE. 10103.

4. Коречков Ю. В. Экономическая эффеккивность использования криптовалюты в российской экономике [Электронный ресурс] / Ю. В. Коречков, П. Б. Целищев // Науковедение : интернет-журн. - 2016. - Т. 8 , № 6. - Режим доступа: http://naukovedenie.ru/PDF/14EVN616.pdf.

5. Маркс К. Капитал. Т. 1 / К. Маркс / / Сочинения / К. Маркс, Ф. Энгельс. - 2-е изд. - М. : Политиздат, 1960. - T. 23. - 907 c.

6. Розенберг Д. И. Комментарий к «Капиталу» К. Маркса / Д. И. Розенберг. - М. : Экономика, 1984. - 720 с. 
7. Nakamoto S. Bitcoin: A Peer-to-Peer Electronic Cash System [Electronic resource] / S. Nakamoto. — Mode of access: https: / / bitcoin.org/bitcoin.pdf.

8. Вахрушев Д. С. Криптовалюта как феномен современной информационной экономики: проблемы теоретического осмысления [Электронный ресурс] / Д. С. Вахрушев, О. В. Железов // Науковедение : интернет-журн. - 2014. - № 5. - Режим доступа: https: / naukovedenie.ru/PDF/127EVN514.pdf.

9. Хайек Ф. А. Частные деньги / Ф. А. Хайек. - М. : Ин-т нац. модели экономики, 1996. - 39 с.

10. Анализ развития и регулирования криптовалют: зарубежный и российский опыт / А. В. Бабкин [и др.] // MИР (Модернизация. Инновации. Развитие). - 2017. - Т. 8, № 4. - C. 554-565. - DOI: 10.18184/20794665.2017.8.4.554-565.

\section{REFERENCES}

1. Zhigas M. G., Kuzmina S. N. Modern trends of using digital technologies in the banking sphere. Evroaziatskoe Sotrudnichestvo. Materialy mezhdunarodnoi nauchno-prakticheskoi konferentsii, Irkutsk, 1415 sentyabrya 2017 g. [Eurasian Cooperation. Materials of International Research Conference, Irkutsk, September 14-15, 2017]. Irkutsk, 2017, pp. 77-86. (In Russian).

2. Evsyukov D. E. Electronic Money and its Influence on the Monetary System. Vestnik Novosibirskogo gosudarstvennogo universiteta. Seriya: Sotsialno-ekonomicheskie nauki = Novosibirsk State University Bulletin. Part: Social and Economic Sciences, 2002, no. 1, pp. 58-71. (In Russian).

3. Pshenichnikov V. V., Babkin A. V. Electronic money as a factor in the development of the digital economy. Nauchno-tekhnicheskie vedomosti Sankt-Peterburgskogo gosudarstvennogo politekhnicheskogo universiteta. Ekonomicheskie nauki $=$ St. Petersburg State Polytechnical University Journal. Economics, 2017, vol. 10, no. 1, pp. 32-42. DOI: 10.18721/JE.10103. (In Russian).

4. Korechkov Y. V., Tselishchev P. B. Economic efficiency of use of cryptocurrencies in the Russian economy. Naukovedenie = Science Studies, 2016, vol. 8, no. 6. Available at: http://naukovedenie.ru/PDF/14EVN616. pdf. (In Russian).

5. Marx Karl. Das Kapital. Kritik der politischen Ökonomie. Erster Band. Buch 1: Der Produktionsprocess des Kapitale. Hamburg, Verlag von Otto Meissner, 1867. (Russ. ed.: Marx K., Engels F. Sochineniya. $2^{\text {nd }}$ ed. Moscow, Gospolitizdat Publ., 1960. Vol. 23. 907 p.).

6. Rozenberg D. I. Kommentarii k «Kapitalu» K. Marksa [Commentary on «The Capital» by Karl Marx]. Moscow, Ekonomika Publ., 1984. 720 p.

7. Nakamoto S. Bitcoin: A Peer-to-Peer Electronic Cash System. Available at: https://bitcoin.org/bitcoin.pdf.

8. Vahrushev D., Zhelezov O. Cryptocurrency as a phenomenon of the modern information economy: problems of theoretical reflection. Naukovedenie =Science Studies, 2014, no. 5. Available at: https: //naukovedenie. ru/PDF/127EVN514.pdf.

9. Hayek F. A. Denationalization of Money. London, 1976. (Russ. ed.: Hayek F. A. Chastnye Dengi. Moscow, National Economy Model Institute Publ., 1996. 39 p.)

10. Babkin A. V., Burkaltseva D. D., Guk O. A., Tyulin A. S. Analysis of the Development and Regulation of crypto-currency: Foreign and Russian Experience. MIR (Modernizatsiya. Innovatsii. Razvitie) = MIR (Modernization. Innovation. Research), 2017, vol. 8, no. 4, pp. 554-565. DOI: 10.18184/2079-4665.2017.8.4.554-565. (In Russian).

\section{Информация об авторах}

Жигас Маргарита Герутисовна - доктор экономических наук, профессор, заведующий кафедрой банковского дела и ценных бумаг, Байкальский государственный университет, г. Иркутск, ул. Ленина, 11, e-mail: GigasMG@bgu.ru.

Кузьмина Светлана Николаевна - аспирант, кафедра банковского дела и ценных бумаг, Байкальский государственный университет, г. Иркутск, ул. Ленина, 11, e-mail: law-ira@mail.ru.

\section{Для цитирования}

Жигас М. Г. Природа и сущность криптовалюты / М. Г. Жигас, С. Н. Кузьмина // Известия Байкальского государственного университета. - 2018. - T. 28, № 2. - C. 201-207. - DOI: $10.17150 / 2500-2759.2018 .28(2) .201-207$.

\section{Authors}

Margarita G. Zhigas - D.Sc. in Economics, Professor, Head of the Department of Banking and Securities, Baikal State University, 11 Lenin St., 664003, Irkutsk, the Russian Federation, e-mail: GigasMG@bgu.ru.

Svetlana N. Kuzmina - Post-graduate student, Department of Banking and Securities, Baikal State University, 11 Lenin St., 664003, Irkutsk, the Russian Federation, e-mail: law-ira@mail.ru.

\section{For citation}

Zhigas M. G., Kuzmina S. N. Nature and Essence of Cryptuals. Izvestiya Baykal'skogo gosudarstvennogo universiteta = Bulletin of Baikal State University, 2018, vol. 28, no. 2, pp. 201-207. DOI: 10.17150/25002759.2018.28(2).201-207. (In Russian). 